\title{
ANÁLISE DE CUSTO-BENEFÍCIO DAS PROPOSTAS DE ALTERAÇÃO DO PROGRAMA TARIFA SOCIAL DE ENERGIA ELÉTRICA ${ }^{1}$
}

Edison B. Silva Filho

Guilherme V. Homsy ${ }^{3}$

\section{SINOPSE}

Este trabalho apresenta simulaçóes dos impactos das principais propostas hoje em debate para alteração do programa de subsídio tarifário para famílias de baixa renda chamado de Tarifa Social de Energia Elétrica (TSEE), que é custeado pela Conta de Desenvolvimento Energético (CDE). Os beneficiários desse programa se encontram identificados na base Sistema de Controle de Subvençôes (SCS), de propriedade da Agência Nacional de Energia Elétrica (ANEEL). Os resultados da simulação mostram que as alteraçóes propostas para a TSEE em projetos de lei tramitando no Congresso acarretarão acréscimo substancial ao montante de subsídios destinado à política pública, cujo custo deverá ser repassado aos demais consumidores de energia, sobretudo, na região centro-sul.

Palavras-chave: subsídio tarifário; famílias de baixa renda; Tarifa Social de Energia Elétrica.

\section{A TARIFA SOCIAL DE ENERGIA ELÉTRICA}

A Tarifa Social de Energia Elétrica (TSEE) é um programa social do governo federal que concede descontos na conta de luz, de forma regressiva, de acordo com faixas de consumo. Famílias de renda mais baixa e de menor consumo mensal de eletricidade têm descontos percentuais maiores, ao passo que famílias de renda mais alta e maior consumo de energia elétrica não são elegíveis para qualquer desconto.

Os subsídios e os custos do programa são repartidos entre os estados, de forma que esses impactos podem ser positivos (benefícios) ou negativos (custos). O saldo global é sempre zero, evidenciando-se que se trata de uma análise de distribuição dos benefícios e custeio da política entre um grupo determinado de agentes.

Os custos incluem a distribuição do custeio dos subsídios da TSEE pelas Unidades da Federação (UFs), que é feito por consumidores convencionais (residenciais e industriais não recebedores de subsídios), cujo peso é diferenciado em termos regionais (Norte e Nordeste contribuem com valor 3,28 vezes menor que Sul, Sudeste e Centro-Oeste, observando-se que Acre e Rondônia são incluídos no Centro-Oeste nesse critério distributivo, em razão de terem sido conectados ao sistema elétrico do restante do país, dispondo, pois, de energia mais barata). Os benefícios, por sua vez, incluem o valor total recebido de TSEE para cada UF, informaçáo obtida na base de dados Sistema de Controle de Subvençóes (SCS).

1. DOI: http://dx.doi.org/10.38116/radar64art3.

2. Técnico de planejamento e pesquisa e coordenador de estudos em tecnologia de informação e comunicação na Diretoria de Estudos e Políticas Setoriais de Inovação e Infraestrutura (Diset) do Ipea.E-mail: <edison.benedito@ipea.gov.br>.

3. Técnico de planejamento e pesquisa na Diretoria de Estudos e Relações Econômicas e Políticas Internacionais (Dinte) do Ipea. E-mail: < guilherme.homsy@ ipea.gov.br>. 


\section{SITUAÇÃO ATUAL E PROPOSTAS}

A atual distribuição de faixas de consumo e descontos é a seguinte: para consumo mensal de até $30 \mathrm{kWh}$, o desconto na tarifa de energia elétrica é de 65\%; na faixa de 30 a $100 \mathrm{kWh}$, o desconto é de 40\%; entre 100 e $220 \mathrm{kWh}$, o desconto é de apenas 10\%; e não há subsídio para o consumo que exceder $220 \mathrm{kWh}$ mensais. ${ }^{4}$

De forma diferenciada, de acordo com Aneel (2016), famílias indígenas e quilombolas inscritas no Cadastro Único e que atendam aos requisitos do programa possuem desconto de $100 \%$ nos primeiros $50 \mathrm{kWh}$ consumidos a cada mês. Devido à indisponibilidade da base do Cadastro Único, esse desconto diferenciado não foi considerado nas simulaçóes dos impactos das propostas.

As quatro propostas de política pública analisadas foram enumeradas a seguir.

1) Projeto de Lei no 260, de 2017, de autoria do Senador Roberto Rocha (Partido Socialista Brasileiro - PSB/ MA), que modifica as faixas de consumo e os percentuais de desconto aplicados aos beneficiários da TSEE para os seguintes: até $50 \mathrm{kWh}$, desconto de $70 \%$ na tarifa; para a faixa de consumo de 50 a $150 \mathrm{kWh}$, desconto de $50 \%$; entre 150 e $250 \mathrm{kWh}$, o desconto alcança apenas $20 \%$; e não haveria desconto para o consumo que excedesse $250 \mathrm{kWh}$ mensais.

2) Projeto de Lei no 469, de 2018, de autoria do Senador Randolfe Rodrigues (Rede/AP), que visa substituir os atuais descontos diferenciados para faixas de consumo por uma isenção linear de cobrança tarifária para consumo mensal de até $70 \mathrm{kWh}$.

3) Proposta da Agência Nacional de Energia Elétrica (Aneel), apresentada em audiência pública na Câmara dos Deputados, que visa substituir os atuais descontos diferenciados para faixas de consumo por uma isenção total de cobrança tarifária para consumo de até $50 \mathrm{kWh}$, e apenas para usuários cadastrados no programa Bolsa Família (BF).

4) Medida Provisória no 950, de 2020, destinada a mitigar os impactos socioeconômicos da pandemia de Covid-19, a qual substitui os atuais descontos diferenciados para faixas de consumo por uma isenção total de cobrança tarifária para consumo de até $220 \mathrm{kWh}$, entre 1/4/2020 e 30/6/2020.5

O que todas as propostas de alteração da TSEE têm em comum é a preocupação em focalizar os benefícios às faixas de menor consumo de energia para usuários de baixa renda. Isso tende a garantir o efeito distributivo do programa, uma vez que deve beneficiar famílias mais carentes e que possuem poucos eletrodomésticos, implicando menor capacidade de consumo de energia mensal.

No caso da proposta da Aneel, a informação de pertencimento ao BF estava disponível apenas em caráter percentual e somente para a faixa de consumo de até $50 \mathrm{kWh}$ por mês, impossibilitando, para este caso, simulaçóes para a unidade consumidora; contrariamente ao que ocorreu com as demais, as simulaçóes, nesse caso, ocorreram apenas com dados agregados pelas UFs e faixas de consumo presentes na proposta.

\section{SIMULAÇÃO E ANÁLISE CUSTO-BENEFÍCIO}

A SCS, de caráter mensal, utilizada para as simulaçóes, é alimentada diretamente pelas distribuidoras de energia elétrica, normalmente, com os dados referentes a cada último mês de semestre (faturaçáo em junho

\footnotetext{
4. A aplicação das faixas de consumo em questão se dá por faixa utilizada, de forma que uma unidade que consuma, por exemplo, 50 kWh em um determinado mês será beneficiada com $65 \%$ de desconto sobre os primeiros $30 \mathrm{kWh}$ consumidos e com $40 \%$ de desconto nos demais 20 kWh. Mais informações sobre 0 programa podem ser encontradas em Aneel (2016).

5. A MP o 950/2020 foi prorrogada até dezembro de 2020, mas os efeitos sobre a TSEE foram limitados até agosto do mesmo ano.
} 
ou dezembro). A base informa, entre outros campos, o consumo, o valor faturado e o valor subsidiado de cada unidade consumidora participante do programa naquele mês de faturação. Para os cálculos realizados nesta nota, empregaram-se os dados referentes ao mês de dezembro de 2018, que abrangem 8.593.827 unidades de consumo. A base em questão possui, de forma identificada, informaçôes em nível de unidade consumidora para as unidades consumidoras beneficiárias.

A estimação dos impactos das propostas de alteração do programa TSEE foi realizada por meio de metodologia que consiste nas seguintes etapas:

- a partir das informaçóes de consumo, valor faturado e valor subsidiado de cada unidade consumidora, estimou-se o valor do preço-sombra ${ }^{6}$ e do preço subsidiado por $\mathrm{kWh}$ para cada unidade consumidora na situação vigente; ${ }^{7}$

- com a estimativa do preço-sombra para cada unidade consumidora, calculou-se o novo subsídio mensal em $\mathrm{kWh}$, o novo valor mensal da fatura e o novo preço subsidiado por $\mathrm{kWh}$ como impacto imediato da alteração da tabela vigente para a tabela da nova situação proposta;

- comparando-se os preços subsidiados (percebidos) para cada unidade consumidora nas duas situaçóes anteriores, obteve-se a variação percentual de preço percebido pela unidade consumidora;

- de posse da variação percentual de preço percebido pela unidade consumidora, calculou-se a alteração percentual da demanda por energia elétrica da referida unidade consumidora tendo com base a elasticidadepreço da demanda por energia elétrica para consumidores de baixa renda, estimada em -0,3819 por Souza et al. (2020) - vale dizer, cada 1\% de acréscimo no preço da energia elétrica percebido por essas famílias resulta em redução de $0,38 \%$ no seu consumo; ${ }^{8}$

- com o novo consumo por unidade consumidora, calculou-se seu novo subsídio mensal em reais póselasticidade e comparou-se com seu subsídio mensal sob a situação vigente; e

- agregou-se essa diferença entre subsídios para todas as unidades consumidoras e distribuiu-se os custos e subsídios mensais da alteração proposta entre as UFs, levando-se em conta os critérios de rateio tarifário da TSEE e a projeção da diferença de subsídios (impacto) causada pela política proposta para o período de doze meses. ${ }^{9}$

Essa metodologia foi aplicada nas simulaçôes para as quatro propostas de modificação da TSEE. A distribuição de custos e subsídios mensais da proposta entre as UFs, bem como a projeção anual dos impactos causados por elas estão calculadas nas tabelas 1 e $2 .{ }^{10}$

6. Em termos econômicos, o preço-sombra corresponde ao custo de oportunidade de uma mercadoria, ou seja, seu preço "verdadeiro" na ausência de falhas de mercado e governo. 0 propósito de estimar o preço-sombra é conhecer o custo efetivo de um bem ou serviço, uma vez que o preço observado no mercado pode sofrer grandes distorções em decorrência da intervenção do governo e das próprias inconsistências de mercado oriundas da assimetria de informação. Neste estudo, empregamos dados de valores pagos às distribuidoras de energia já descontados de impostos e subsídios como forma de estimar o preçosombra do fornecimento de energia elétrica aos consumidores de baixa renda beneficiados pelo programa TSEE, que constam na base de dados SCS da Aneel.

7. Exceto para a proposta da Aneel, para a qual o valor do preço-sombra foi obtido, para cada combinação de UF e faixa de consumo, a partir dos valores médios de consumo, subsídio e fatura por unidade consumidora. Todos os passos seguintes, no caso da proposta da Aneel, devem ser entendidos como sendo aplicados tendo como base tais valores médios, e não os dados em nível de unidade consumidora.

8. Nos casos de políticas propostas que prevejam isenção total por tempo indeterminado (PL no 469/2018 e proposta da Aneel), considerou-se que, se o consumo calculado após a aplicação da elasticidade-preço da demanda por energia elétrica for inferior ao limite de consumo com isenção total, tal consumo calculado deve ser ajustado ao referido limite de consumo.

9. Ainda que a MP no 950/2020 tenha tido validade prevista de apenas três meses, havia expectativa de que fosse prorrogada em razão do agravamento da crise, motivo pelo qual a simulação dos efeitos das alterações propostas à TSEE também foram estimadas para até um ano.

10. As tabelas 1 e 2 mostram, nas primeiras colunas, os valores atuais de custos e benefícios mensais da TSEE distribuídos em âmbito regional, bem como o resultado líquido para cada UF. Ao final, a soma desses valores corresponde ao custo total mensal da política, que hoje alcança cerca de R\$195 milhões. Nas colunas seguintes, são apresentados os efeitos das novas políticas propostas para a TSEE, que, com exceção da proposta da Aneel (não oficial), causarão aumento no valor dos subsídios, com consequente encarecimento da política pública. Por fim, na última linha das tabelas, constam os valores de impacto anual adicional dessas propostas, que consistem na diferença entre o valor total mensal e o custo atual da política (primeiras colunas), multiplicado por doze para ser anualizado. 


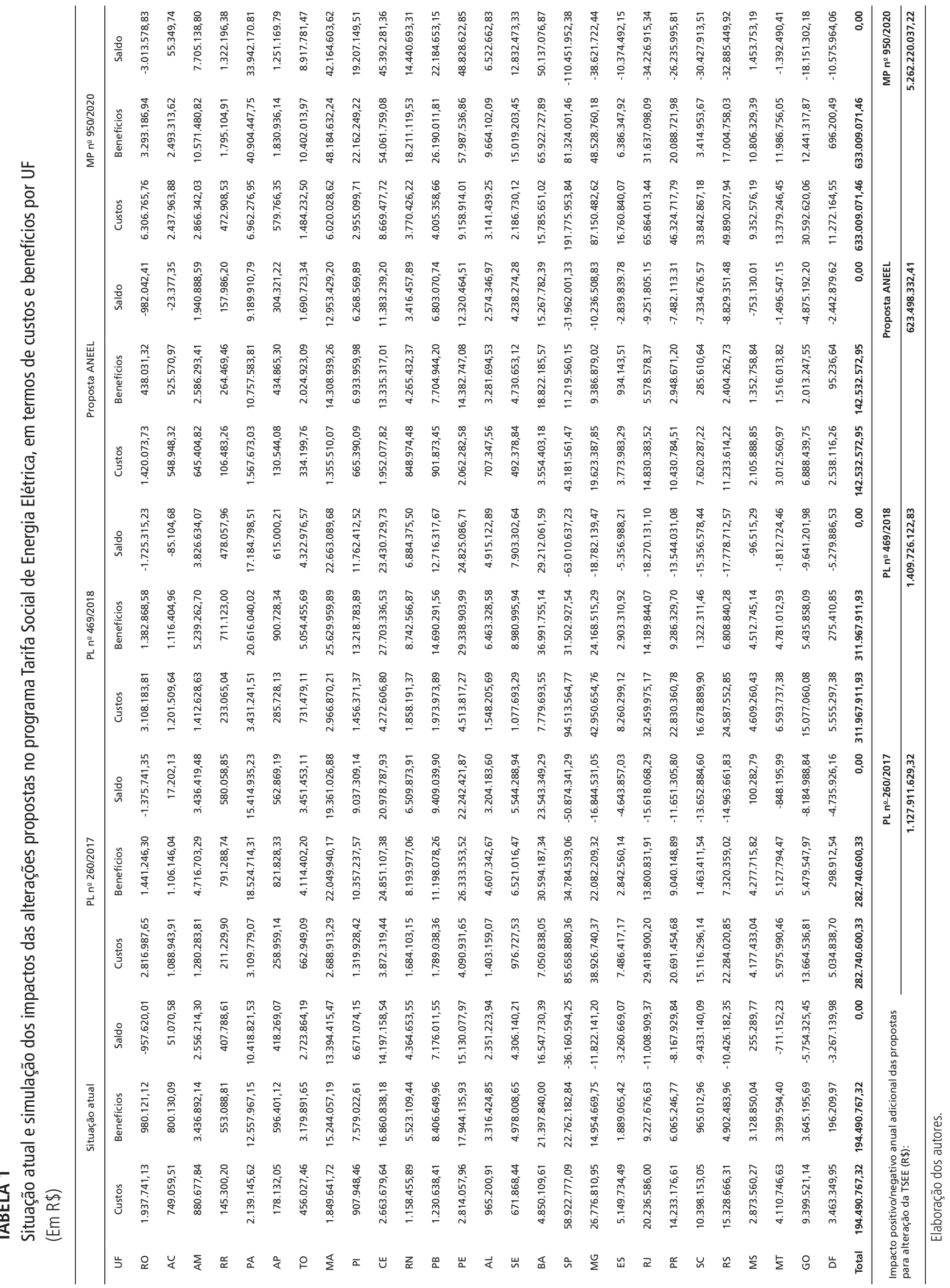


Observamos que as UFs que mais são penalizadas na distribuição de custos do programa TSEE pertencem às regiôes Sul e Sudeste, além de Rondônia, pelo fato de esta ser incluída na mesma categoria de rateio tarifário daqueles (3,28, valor constante na Conta de Desenvolvimento Energético - CDE para 2019). No Centro-Oeste, o efeito é misto: Goiás e Distrito Federal claramente são penalizados em grande monta, mas Mato Grosso e Mato Grosso do Sul se beneficiam marginalmente. Por seu turno, as UFs do Norte e Nordeste são amplamente beneficiadas no rateio dos custos da TSEE cobrados dos consumidores convencionais.

É possível refinar essa análise de impacto utilizando-se, por exemplo, estimativas diferenciadas de elasticidadepreço da demanda para cada faixa de consumo de energia elétrica. Também contribuiria para esse fim a correção de problemas encontrados na base de dados SCS, em especial, a grande quantidade de dados nulos para consumo e fatura nas faixas mais elevadas de consumo médio dos beneficiários da TSEE. Este último fator foi responsável por algumas inconsistências significativas na análise para o comportamento do mercado da faixa de alto consumo de UFs do Nordeste e até mesmo para o Rio de Janeiro (que tem uma participação expressiva no total nacional) no período analisado.

\section{CONCLUSÕES E RECOMENDAÇÕES}

Esta nota técnica mostrou a situação atual e estimou os impactos em termos de aumento do custo dos subsídios e efeitos distributivos das principais propostas de alteração da TSEE.

A principal conclusão é que os aumentos propostos no subsídio ao consumo de energia de famílias de baixa renda produzirão impactos significativos para a CDE, além de ampliarem as divergências entre estados beneficiários líquidos e custeadores líquidos.

Embora esses efeitos redistributivos possam ser desejáveis sob a ótica da equidade econômica, o elevado custo de expansão da política suscita questionamentos quanto à necessidade de maior focalizaçáo de seus benefícios, de modo a não apenas se alcançarem as camadas mais pobres da população, mas também se evitar que consumidores de baixa renda de estados do centro-sul, que hoje estâo excluídos do programa, acabem sendo penalizados em excesso no seu custeio.

\section{REFERÊNCIAS}

ANEEL - AGÊNCIA NACIONAL DE ENERGIA ELÉTRICA. Tarifa Social de Energia Elétrica - TSEE. Brasília: Aneel, 12 jan. 2016. Disponível em: <https://www.aneel.gov.br/tarifa-social-baixa-renda>. Acesso em: 21 nov. 2019.

SOUZA, J. G. M. et al. Elasticidade-preço da demanda de energia elétrica domiciliar no Brasil por classe de renda. Ipea, 2020. No prelo. (Texto para discussão). 